\title{
Quench Performance of Fermilab/General Dynamics Built Full Length SSC Collider Dipole Magnets
}

J. Strait, D. Orris, P. Mazur, M. Bleadon, R. Bossert, J. Carson, S. Delchamps, S. Gourlay, R. Hanft, W. Koska, M. Kuchnir, M. Lamm, J. Ozelis and M. Wake

Fermi National Accelerator Laboratory

P.O. Box 500, Batavia, Illinois 60510

\author{
A. Devred, J. DiMarco, J. Kuzminski, W. Nah, T. Ogitsu, \\ M. Puglisi, J. Tompkins, Y. Yu, Y. Zhao and H. Zheng \\ SSC Laboratory \\ 2550 Beckleymeade Avenue, Dallas, Texas 75237
}

April 1992

Presented at the Fourth Annual 1992 International Industrial Symposium on the Super Collider, New Orleans, Louisiana, March 4-6, 1992. 


\section{Disclaimer}

This report was prepared as an account of work sponsored by an agency of the United States Government. Neither the United States Government nor any agency thereof, nor any of their employees, makes any warranty, express or implied, or assumes any legal liability or responsibility for the accuracy, completeness, or usefulness of any information, apparatus, product, or process disclosed, or represents that its use would not infringe privately owned rights. Reference herein to any specific commercial product, process, or service by trade name, trademark, manufacturer, or otherwise, does not necessarily constitute or imply its endorsement, recommendation, or favoring by the United States Government or any agency thereof. The views and opinions of authors expressed herein do not necessarily state or reflect those of the United States Government or any agency thereof. 


\title{
QUENCH PERFORMANCE OF FERMILAB/GENERAL DYNAMICS BUIL'T FULL LENGTH SSC COLLIDER DIPOLE MAGNETS
}

\author{
J. Strait ${ }^{1}$, D. Orris ${ }^{1}$, P.O. Mazur ${ }^{1}$, M. Bleadon ${ }^{1}$, \\ R. Bossert ${ }^{1}$, J. Carson 1 , S.W. Delchamps ${ }^{1}$, \\ A. Devred 2 , J. DiMarco 2 , S. Gourlay1, R.Hanft ${ }^{1}$, \\ W. Koska1, M. Kuchnir ${ }^{1}$, J. Kuzminski ${ }^{2}$, \\ M.J. Lamm 1 , W. Nah' ${ }^{2}$, T. Ogitsu' ${ }^{2}$, J. Ozelis 1 , \\ M. Puglisi ${ }^{2}$, J.C. Tompkins ${ }^{2}$, M. Wake ${ }^{1}$, \\ Y. Yu2 ${ }^{2}, Y$. Zhao $^{2}$, H. Zheng ${ }^{2}$. \\ 1 Fermi National Accelerator Laboratory \\ P.O. Box 500 \\ Batavia, IL 60510 USA, \\ 2SSC laboratory \\ 2550 Beckleymeade Avenue \\ Dallas, TX 75237 USA
}

\section{INTRODUCTION}

In this paper we present results of quench testing of full length SSC dipole magnets at Fermilab. The data are from the first six of a series of thirteen $15 \mathrm{~m}$ long, $50 \mathrm{~mm}$ aperture SSC dipole magnets which are being built and tested at Fermilab. These magnets were designed jointly by Fermilab, Brookhaven Laboratory, Lawrence Berkeley Laboratory and the SSC Laboratory. Among the major goals for this series of magnets are to transfer magnet production technology to the lead vendor for the Collider Dipole Magnet, the General Dynamics Corporation, and to demonstrate industrial production by the vendor. The first magnet in the series, DCA311, was built by Fermilab technicians to establish assembly procedures. The second magnet, DCA312, was the "technology transfer magnet" and was built jointly by Fermilab and General Dynamics technicians. The next seven, DCA313-319 are being built by General Dynamics personnel using Fermilab facilities and procedures. However, Fermilab personnel still operate the major tooling, provide the welders, perform assembly of items that would not be part of production magnets (e.g. voltage taps), and oversee the QA program. Five of these 7 GD-built magnets will be used in the Accelerator Systems String Test (ASST) to be carried out in Dallas later this year. The last four magnets, DCA320-323, are being built by Fermilab alone.

The design of this magnet has been previously described $1,2,3,4$. It consists of a $\cos \theta$ style coil clamped by $17 \mathrm{~mm}$ wide stainless steel collars. A vertically-split yoke is employed to provide mechanical support to the collars near the horizontal mid-plane to limit deflections

* Operated by the Universities Research Association, Inc. for the U..S. Department of Energy. 
under the Lorentz force to $<0.02 \mathrm{~mm}$. The coil ends have current blocks, defined by machined G10 spacers, that match those of the 2-dimensional cross-section. The innerouter coil splice is made outside the coil at the lead end. The coil ends are clamped by a collet assembly consisting of a 4-piece G10 insulator with a tapered outer surface and an aluminum cylinder with a tapered inner surface. The coil end is preloaded axially against the magnet end plate with four set screws at each end to provide axial restraint under excitation.

The magnets are instrumented with 53 voltage taps. These are concentrated in the six inner coil turns nearest the pole and allow determination of quench locations to within several centimeters for quenches that originate in these turns. Strain gauge load cells measure coil azimuthal stress at the pole and axial force at the coil ends 5 . The azimuthal coil stress gauges are placed at two locations, where the average coil size is largest and smallest. Strain gauges on the magnet shell measure axial and azimuthal stress changes with excitation. The magnet tests were carried out at the Fermilab Magnet Test Facility 6,7.

In the second section of this paper the spontaneous quench performance and the temperature dependence of the quench current are presented. Tests of the quench protection system are presented in section three. The dependence of the quench current on the ramp rate is compared with measured energy loss per excitation cycle in the fourth section. Other test results from these magnets are presented in two companion papers ${ }^{8.9}$.

\section{SPONTANEOUS QUENCH PERFORMANCE}

Figure 1 displays the quench histories of the six magnets tested. Unless otherwise noted, all quenches in this plot occurred at a ramp rate $\leq 4 \mathrm{~A} / \mathrm{sec}$. In most cases, the first quench of a sequence for a magnet occurred at a nominal ramp rate of $16 \mathrm{~A} / \mathrm{sec}$ during a run to collect strain gauge data as a function of current. In such a run the magnet is ramped up in steps of roughly $500 \mathrm{~A}$ and strain gauge data are collected at each step. The step-wise nature of the ramp yields an average ramp rate of $<5 \mathrm{~A} / \mathrm{sec}$ above $5000 \mathrm{~A}$. Quenches $2-5$ of the first cooldown of DCA311 were taken at $16 \mathrm{~A} / \mathrm{sec}$. Because of the significant ramp rate dependence of the quench current (see below) these quenches are at a lower current than the others. Once the ramp rate sensitivity was recognized, the lower ramp rate was used for all spontaneous quench tests.

On the initial test cycle at $4.35 \mathrm{~K}$ (Fig. 1a) all magnets exceeded the SSC operating current of $6600 \mathrm{~A}(6.7 \mathrm{~T})$ on the first or second quench, and by the second quench were within about $100 \mathrm{~A}$ of the conductor limit. DCA313, 314 and 316 each had one quench below the operating current. In the first two of these magnets the quench occurred, within a measurement uncertainty of $\pm 15 \mathrm{~mm}$, at the same location: in the pole turn of the inner coil on the side opposite the splice within $\pm 15 \mathrm{~mm}$ of the collar - end clamp boundary. The cause of the training quenches is unknown. The first quench in DCA316 occurred in the uninstrumented portion of the inner coil, so a precise quench location cannot be determined.

Figure $1 \mathrm{~b}$ shows the initial quench currents at $4.35 \mathrm{~K}$ on the second cooldown. All magnets reached within 50-60 A of the conductor limit on the first quench. Much of the quench-to-quench variation in the current results from temperature fluctuations. One of the two test stands used has poorer temperature control than the other and all the even numbered magnets were tested on this stand. Figure 2 plots the quench current versus the magnet temperature for all quenches with $\mathrm{dI} / \mathrm{dt} \leq 4 \mathrm{~A} / \mathrm{sec}$; however, the three low training quenches are off scale. The temperature is measured at the two ends of the magnet and the higher of the two (normally at the helium outlet end) is used. Data from the first (Figs. 2a and 2c) and second (Figs. $2 \mathrm{~b}$ and $2 \mathrm{~d}$ ) are plotted separately. Magnets with inner coil conductor made by Supercon (DCA311) and Oxford Superconducting Technology (DCA316) are in Figures 2a and $2 \mathrm{~b}$ and those with conductor made by Intermagnetics General Corporation (IGC) are in Figures $2 c$ and $2 d$. Shown also are the expected temperature dependences using Green's paramaterization of the critical surface ${ }^{10}$.

On the second cooldown magnets are tested at $3.8 \mathrm{~K}$ and then $3.5 \mathrm{~K}$. The low temperature quench results are shown in Figs. 1c, $2 \mathrm{~b}$ and $2 \mathrm{~d}$. Only DCA315 exhibited training at $3.8 \mathrm{~K}$. (The low quench in DCA316 results from a temperature fluctuation as can be seen in Fig. 2b.) Only DCA312 had one initial training quench at $3.5 \mathrm{~K}$. However, DCA314 "de-trained" after reaching the conductor limit on the first $3.5 \mathrm{~K}$ quench. It however returned to normal behavior when the temperature was restored to $4.35 \mathrm{~K}$. The cause of this behavior is unknown and limitations on the testing time prevented further investigation of the effect. Strain gauge data ${ }^{8}$ were taken at currents up to $8 \mathrm{kA}$ while 
ramping to the first $3.5 \mathrm{~K}$ quench. These data indicate that the coils remained azimuthally loaded, that the yoke mid-plane gap remained closed, and that the axial force transfer to the shell was similar to the other magnets. Among all magnets, four of the five mechanically induced (training) quenches at low temperature occurred in the outer coil. Again, the limited testing time has not allowed us to understand this behavior.

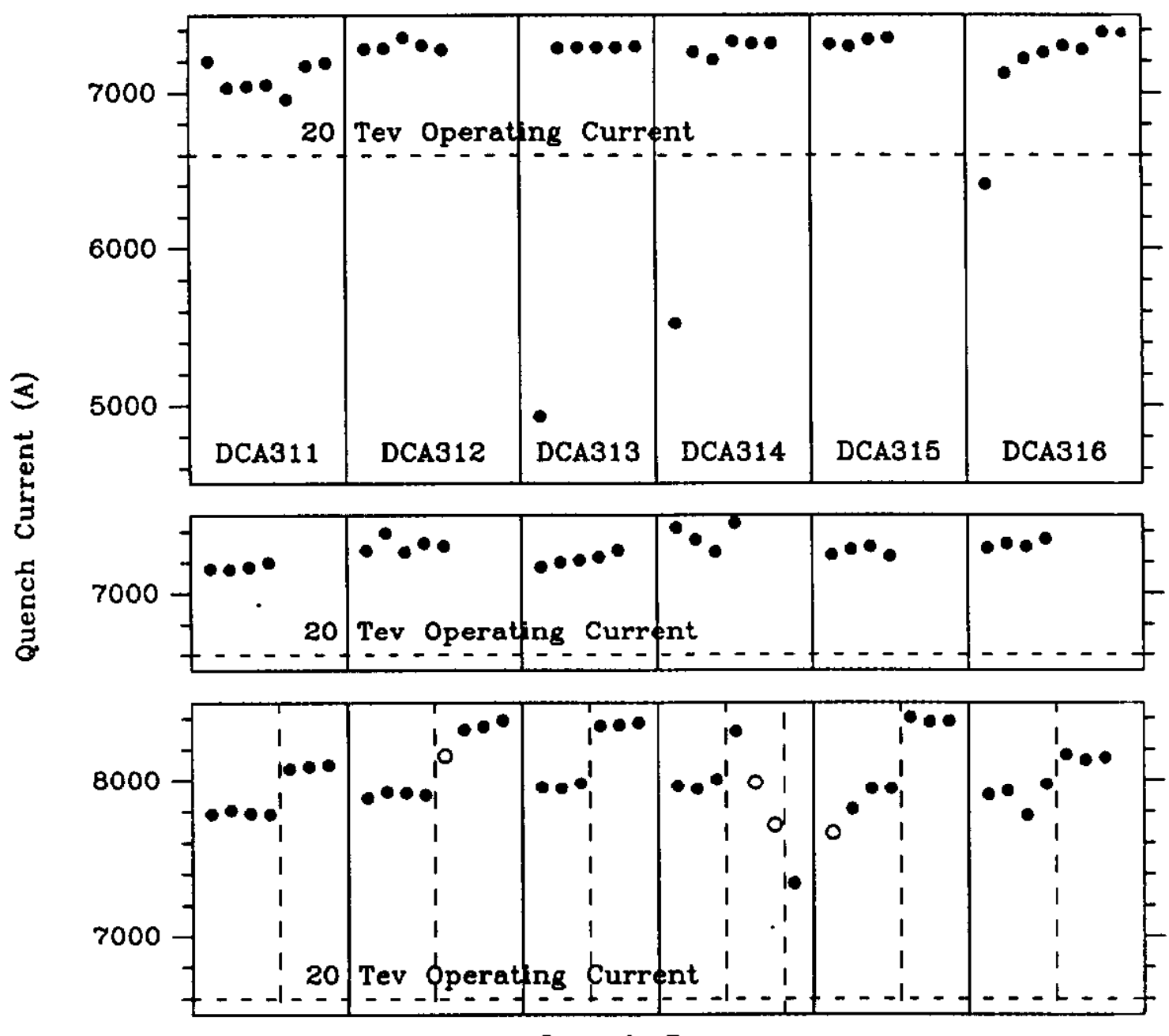

(a)

(b)

(c)

Figure 1. Spontaneous quench histories at $4.35 \mathrm{~K}$ on the first cooldown (a) and at $4.35 \mathrm{~K}$ (b) and $3.8 \mathrm{~K}$ and $3.5 \mathrm{~K}$ (c) on the second cooldown. Closed (open) circles are quenches that originate in the inner (outer) coil. In (c) the data to the left (right) of the vertical dashed line are at $3.8 \mathrm{~K}(3.5 \mathrm{~K})$. To the right of the second dashed line for DCA314 the temperature is $4.35 \mathrm{~K}$.

\section{QUENCH PROTECTION SYSTEM TESTS}

Quench protection is provided primarily by heater strips ${ }^{11}$ mounted between the layers of Kapton insulation between the outer coils and the collars. Two of the four heaters, located in opposite quadrants, are wired in parallel; the other two are spares and are not used. When a quench is detected the power supply is turned off, causing the magnet to discharge at an initial rate of about $1 \mathrm{kA} / \mathrm{s}(1 \mathrm{~T} / \mathrm{s})$ into the resistance of the power system, and the protection heaters are energized by discharging a capacitor bank of 36 to $52 \mathrm{mf}$ charged to $400-450 \mathrm{~V}$. On the first magnet tested the characteristics of the heaters were established by varying the energy deposited until the coil was observed to quench at $4.35 \mathrm{~K}$ with a time delay $<0.20 \mathrm{~s}$ at $2 \mathrm{kA}$ and $<0.12 \mathrm{~s}$ at $5 \mathrm{kA}$. The time integral of the current squared (MIITs, see below) from the time the heaters were energized is $<4$ and $10 \times 10^{6} \mathrm{~A}^{2} \mathrm{~s}$ respectively. At $4.35 \mathrm{~K}$ a $36 \mathrm{mf}$ capacitor charged to $440 \mathrm{~V}$ was used, resulting in a time constant of $0.24 \mathrm{~s}$ and an energy deposition per strip within $0.12 \mathrm{~s}$ of $1 \mathrm{~kJ}$. For lower temperature operation a larger capacitance is used to give a larger energy deposition with a longer time constant. 


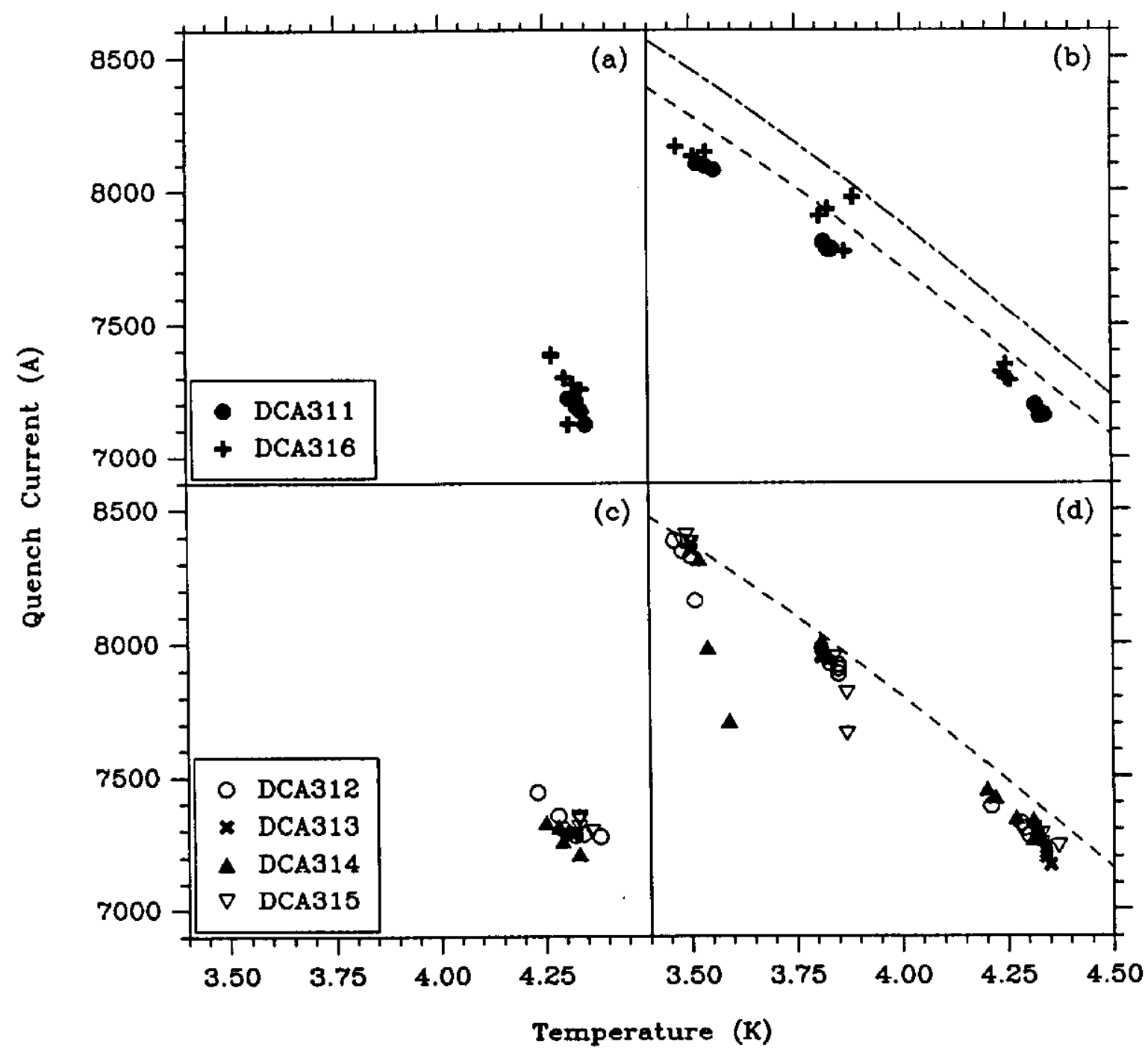

Figure 2. Quench current versus test temperature on the first (a and c) and second (b and d) cooldowns. The curves in (b) and (d) indicate the calculated magnet critical currents. In (b) the dashed (dot-dashed) curve is the calculation for DCA311 (DCA316).

In an adiabatic approximation the peak temperature of the conductor is given by the time integral of the current squared from the time the quench begins. This integral is conventionally expressed in units of $10^{6} \mathrm{~A}^{2} \mathrm{~s}$ and is called "MIITs." At low current the MIITs are low because the current is low, and near the critical current the MIITs tend to decrease since the quench propagates rapidly. The maximum MIITs, and therefore the maximum conductor temperature, occur at some intermediate current. In these magnets the outer coil, which has less copper in each turn, reaches a higher temperature for the same number of MIITs. An operation limit of 15 MIITs, corresponding in the adiabatic limit to a peak temperature of $620 \mathrm{~K}$ for outer coil quenches and $200 \mathrm{~K}$ for inner coil quenches, is applied to these magnets. To determine the maximum MIITs as a function of magnet current a series of quenches were induced at $4.35 \mathrm{~K}$ in each magnet using a spot heater located near one end of the inner coil mid-plane. The quench protection heaters are energized when the quench was detected. (The time delay between the first resistive voltage and quench detection varies from about $45 \mathrm{msec}$ at $4.5 \mathrm{kA}$ and $20 \mathrm{msec}$ at $6.5 \mathrm{kA}$ to $<5 \mathrm{msec}$ near the critical current.) In magnet DCA311 the heaters were energized $35 \mathrm{msec}$ after the quench was detected; in all other magnets no delay was used. The results of this test are shown in Fig. 3. The maximum MIITs occurs near $6 \mathrm{kA}$, or $80-85 \%$ of the critical current, in all the magnets, and there is a roughly $20 \%$ spread in the MITS among the magnets. 
The extent to which the heaters are required for quench protection can be tested by progressively delaying their energization. The MIITs as a function of the heater delay, for spot heater induced quenches at $6 \mathrm{kA}$, is plotted in Fig. 4. For delays $\leq 100 \mathrm{msec}$ the MITTs vary linearly with the delay time. For longer delays the MIITs increase less rapidly and for several of the magnets the MIITs appear to be approaching a constant value for delays around $150 \mathrm{msec}$, with some magnets above and some below the limit of 15 MIITs. Thus, while at least some of the magnets appear to be self-protecting for single magnet tests, the series as a whole cannot be considered self-protecting.

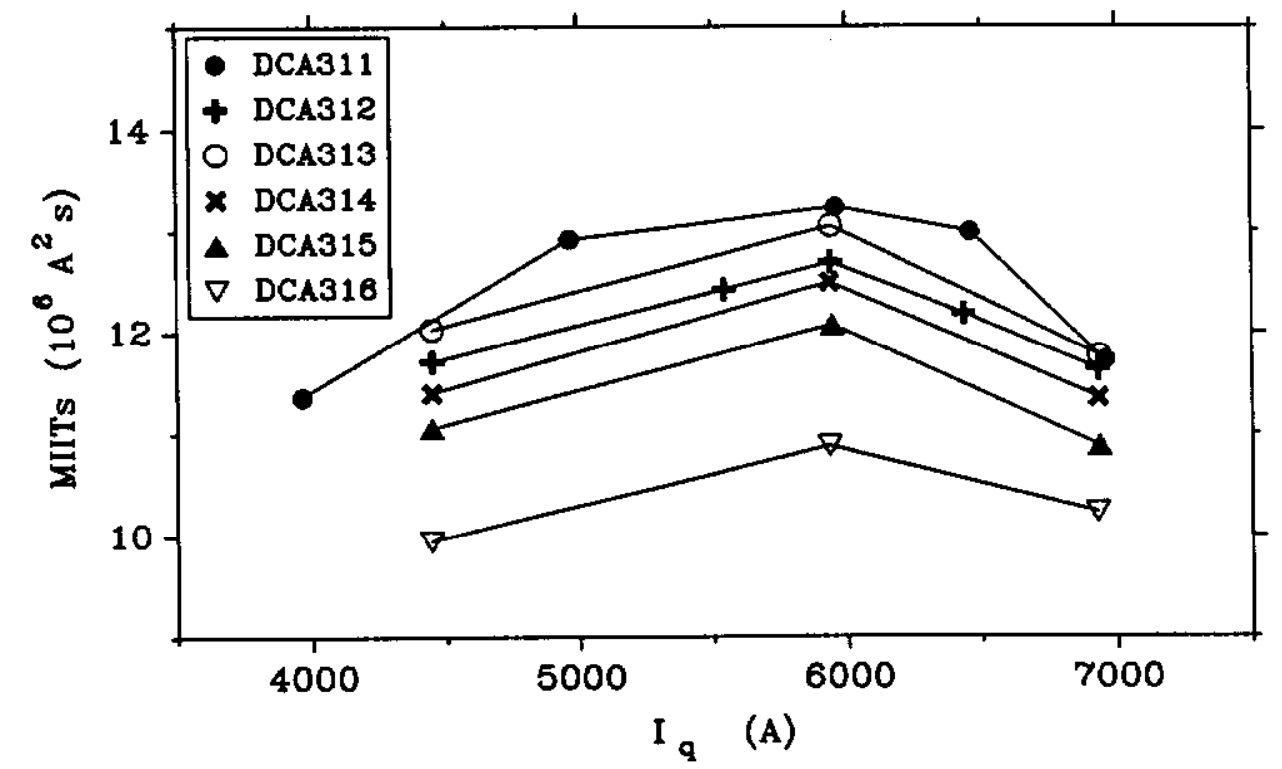

Figure 3. Time integral of $\mathrm{I}^{2}$ (MITs) versus quench current $\left(\mathrm{I}_{\mathrm{q}}\right)$ for spot heater induced quenches. The protection heater firing delay is $35 \mathrm{msec}$ for DCA311 and zero for all other magnets.

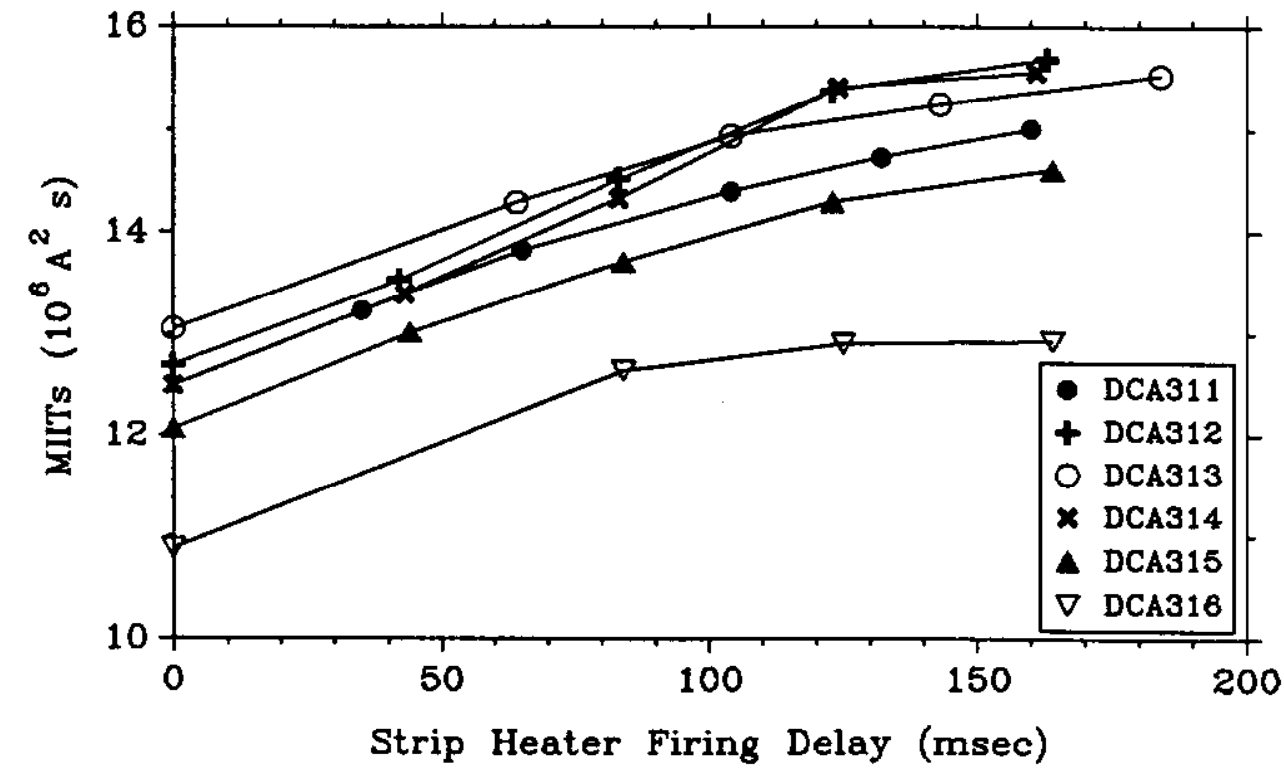

Figure 4. Time integral of $\mathrm{I}^{2}$ (MIITs) versus protection heater delay for spot heater induced quenches at $6 \mathrm{kA}$.

\section{RAMP RATE DEPENDENCE AND AC LOSS MEASUREMENTS}

Eddy current heating of the cable copper matrix while the magnet is being ramped can increase the conductor temperature and reduce the quench current. The quench current as a function of ramp rate is shown in Fig. 5. The quench current is very sensitive to ramp rate in these magnets. In four of the magnets (DCA312-315) the quench current is roughly constant 
up to $\mathrm{dI} / \mathrm{dt}=25 \mathrm{~A} / \mathrm{s}$ and then drops rapidly to, in the most extreme case, roughly $2 \mathrm{kA}$ at 200 $\mathrm{A} / \mathrm{sec}$. In the other two magnets the quench current drops more rapidly at lower ramp rates, being noticeably reduced even at $16 \mathrm{~A} / \mathrm{s}$, but then decreases less rapidly at higher ramp rates. (In DCA 316 the first quench at $200 \mathrm{~A} / \mathrm{s}$ was about $600 \mathrm{~A}$ higher than expected from an extrapolation of lower ramp rate data. A second $200 \mathrm{~A} / \mathrm{s}$ quench was at the expected current. The cause of this behavior is unknown.) In all cases the higher ramp rate quenches originate in the uninstrumented turns closer to the mid-plane of the inner coil.

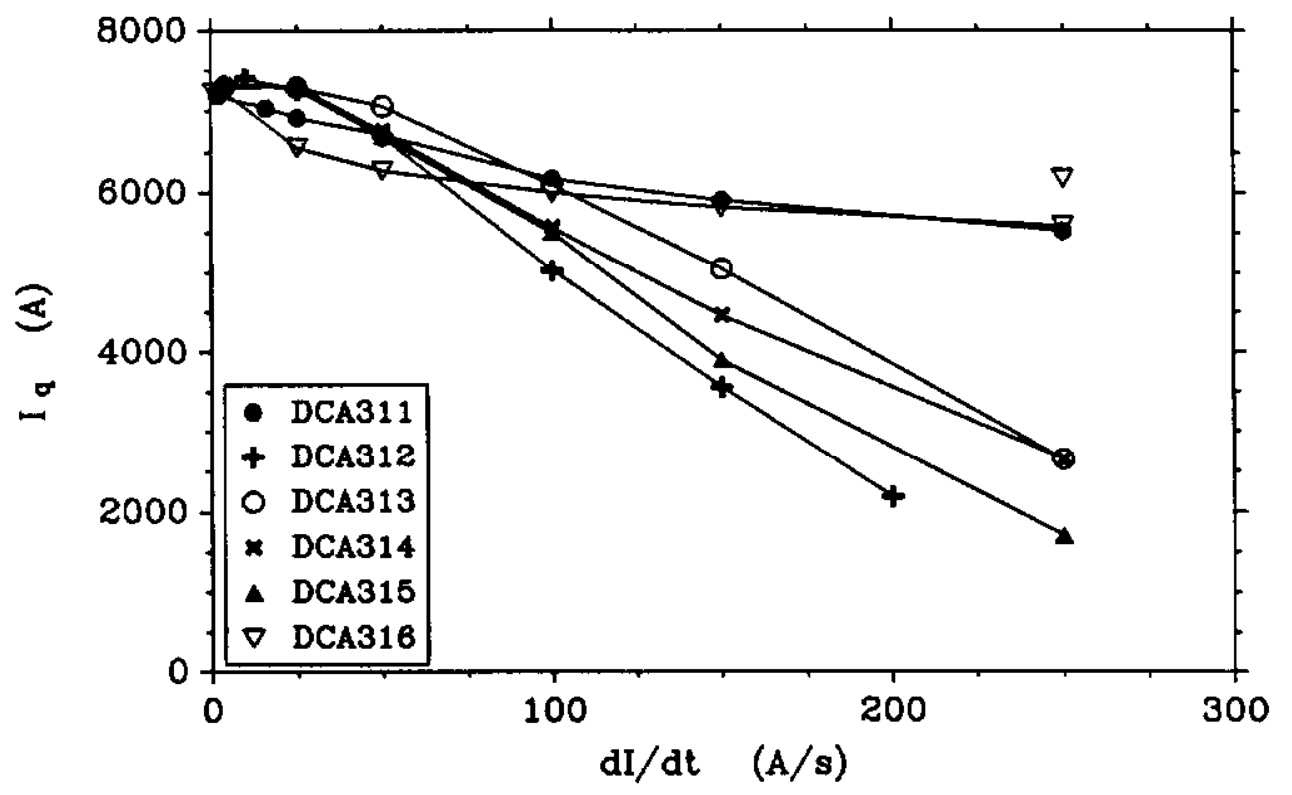

Figure 5. Quench current $\left(\mathrm{I}_{\mathrm{q}}\right)$ versus ramp rate (dI/dt).

The dramatically different behavior of these two sets of magnets correlates with the vendor of the superconducting wire used in the inner coils: DCA312-315 use IGC conductor, DCA311 uses Supercon conductor, and DCA316 uses Oxford conductor. It is not known what different wire processing parameters result in the different magnet behavior. There is also considerable variation in the high ramp rate behavior among the four magnets made with cable from the same vendor, although the wire, cable and coil manufacturing processes are all nominally the same for these magnets. It appears that there are processing variable which effect the ramp rate sensitivity which are not adequately controlled. While this degree of sensitivity is is unlikely to be a problem for the Collider, which ramps at $4 \mathrm{~A} / \mathrm{s}$, it may be a problem during fast ramp-down if magnets with modestly more eddy current losses than these are manufactured ${ }^{12}$. Also, similar magnets are to be used in the High Energy Booster, which must ramp at $70 \mathrm{~A} / \mathrm{s}$, and magnets of this quality would clearly degrade its performance.

To learn whether this ramp rate sensitivity and the magnet-to-magnet variations result from large eddy current heating or from poor cooling, energy loss measurements were performed on four of the magnets. Measurements were made using the system described in Ref. 13, which simultaneously samples the magnet voltage and current using fast integrating digital multimeters. Data were taken using a simple sawtooth ramp between 500 and 5000 A with ramp rates varying from 30 to $150 \mathrm{~A} / \mathrm{s}$. Data were taken from two complete cycles at each ramp rate after at least three full cycles had been completed. The measurements are plotted in Fig. 6. Shown also is the average of measurements of three $1.5 \mathrm{~m}$ model magnets ${ }^{14}$ multiplied by 10 . (The ratio of superconductor volume in long to short magnets is 10 and the ratio of magnetic lengths is 11.) A linear least squares fit is done to the data from each magnet. The $\mathrm{dI} / \mathrm{dt}=0$ intercept gives the superconductor and iron hysteresis loss, and the slope characterizes the eddy current losses. The results are summarized in Table I. The 
Table 1. AC Loss Measurements

\begin{tabular}{|ccc|}
\hline & Hysteresis & $\begin{array}{c}\text { Eddy Current } \\
\text { Loss (J/A/S) }\end{array}$ \\
\hline DCA 311 & Loss $(J)$ & $16.2 \pm 1.3$ \\
DCA 312 & $530 \pm 130$ & $57.3 \pm 3.6$ \\
DCA 314 & $1160 \pm 220$ & $35.1 \pm 1.3$ \\
DCA 315 & $840 \pm 120$ & $50.9 \pm 2.2$ \\
\hline Average & $780 \pm 150$ & \\
\hline Short Magnet Average & $780 \pm 130$ & $0.64 \pm 0.04$ \\
\hline
\end{tabular}

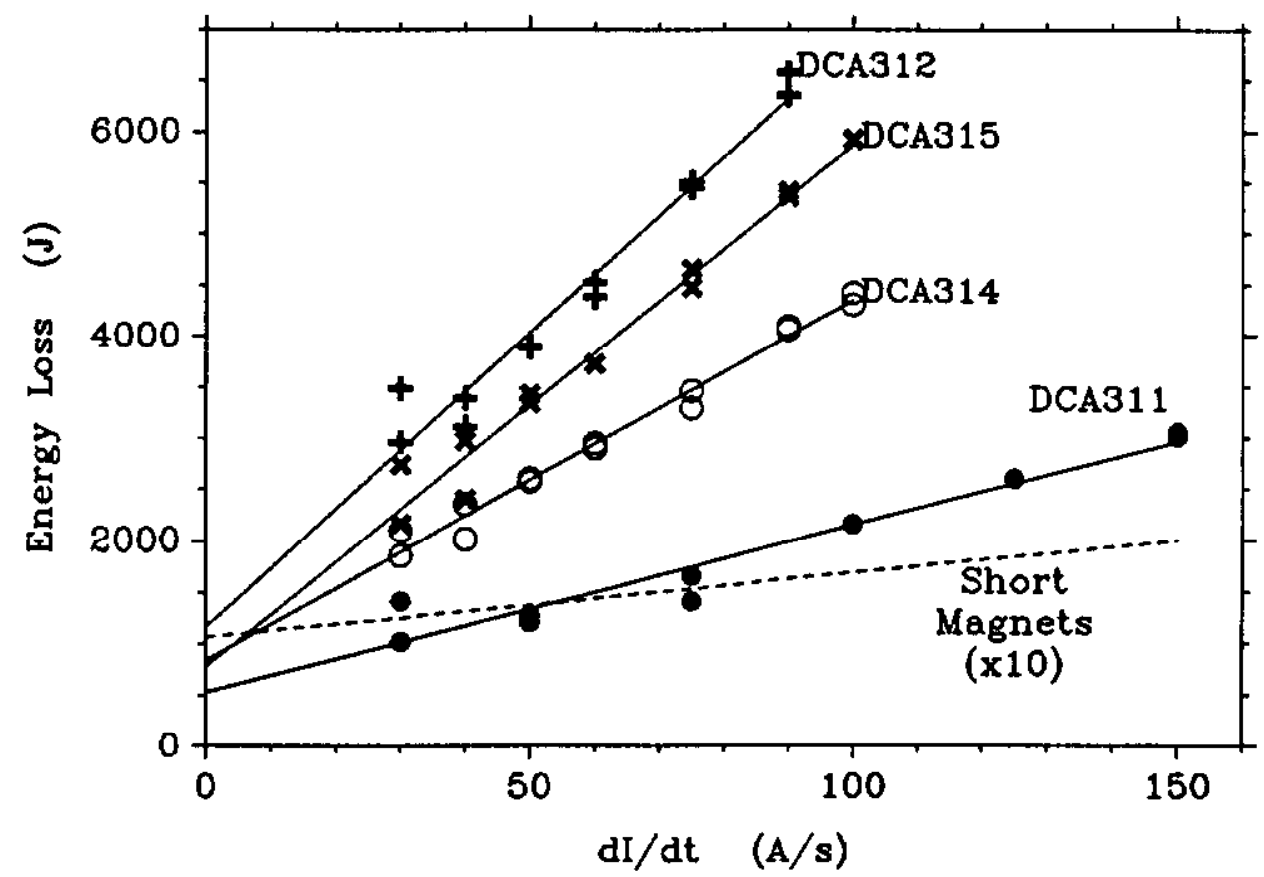

Figure 6. Energy loss measurements for a 500-5000-500 A cycle versus ramp rate (dI/dt).

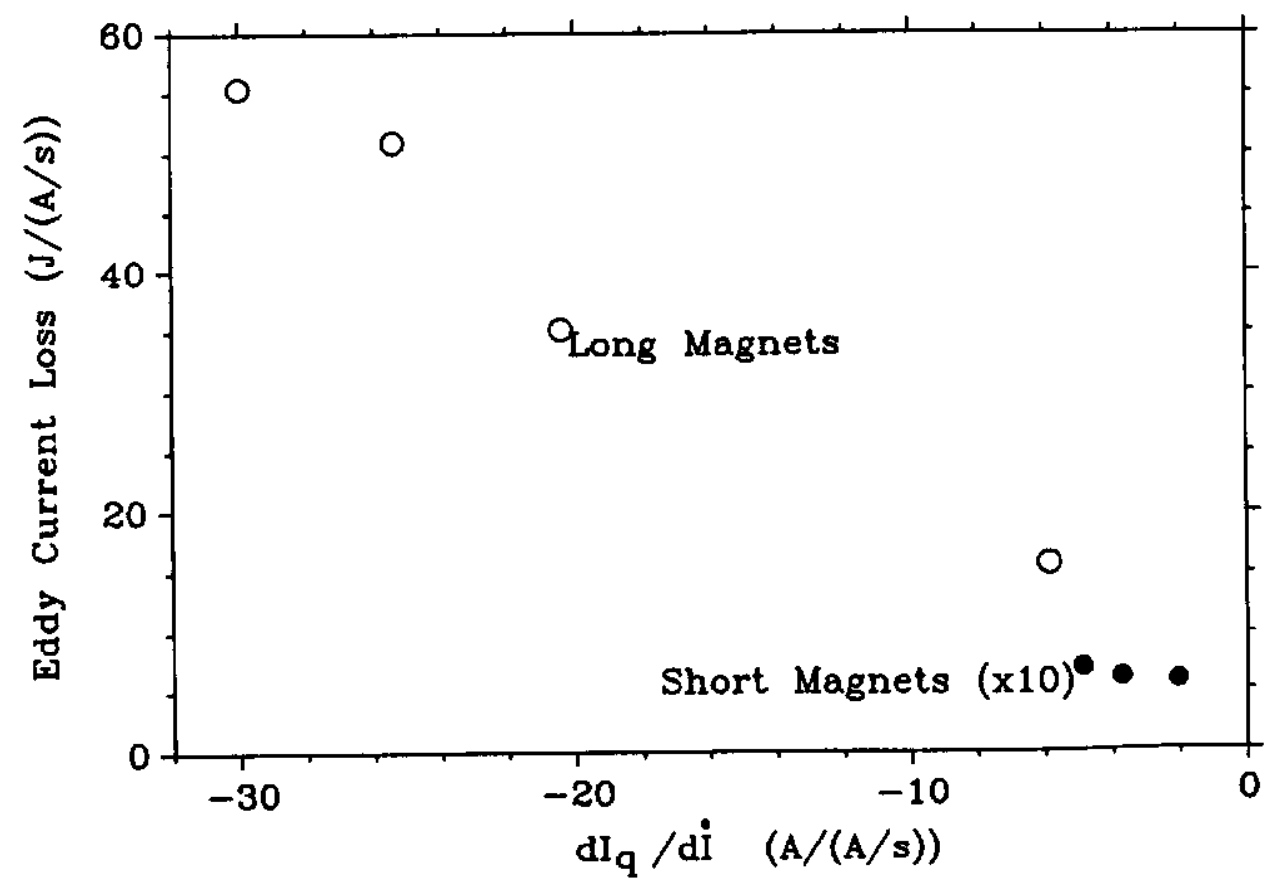

Figure 7. Eddy current loss versus quench current ramp rate slope $\left(\mathrm{dI}_{\mathrm{q}} / \mathrm{di}\right)$ 
hysteresis losses are, within estimated errors, consistent among the magnets, but there is a wide variation among the eddy current losses. Those magnets with the greatest ramp rate sensitivity also show the greatest eddy current loss. This relation can be quantified by fitting a straight line to the quench data in Fig. 5 for $\mathrm{dI} / \mathrm{dt} \geq 50 \mathrm{~A} / \mathrm{s}$. The eddy current slope is plotted as a function of the quench current slope in Fig. 7 and an essentially linear relation is observed. The short magnets eddy current data, when multiplied by 10 , lie on the same line. Thus we conclude that the ramp rate sensitivity and its magnet-to-magnet variation results dominantly from eddy current heating rather than from poor and variable cooling.

\section{CONCLUSIONS}

Six full length $50 \mathrm{~mm}$ aperture SSC dipole magnets have been built and tested at Fermilab. The spontaneous quench performance is good, with three of the six magnets comfortably exceeding the operating current without quenching, and the remaining three having one quench each below the operating current. All magnets quench at or very near their conductor limit on the first or second quench. At $3.5 \mathrm{~K}$ all magnets reached fields above $8 \mathrm{~T}$. Tests of the quench protection heaters were performed which indicate that they are quite adequate for single magnet tests. However, the large energy deposition required may make the use of conventional capacitor discharge firing units impractical in a string of magnets in which several heaters are wired in series. The quench current is quite sensitive to ramp rate in these magnets and the ramp rate sensitivity correlates well with eddy current loss measurements. The surprisingly large eddy current losses and the significant magnet-tomagnet variations indicate that some parts of the manufacturing chain are not adequately controlled. Ramp rate sensitivity and $\mathrm{AC}$ losses at this level are probably not a problem for the Collider, but could be a problem for the High Energy Booster.

\section{ACKNOWLEDGEMENTS}

We would like to thank the Fermilab Superconducting Magnet Fabrication Group and of the General Dynamics Space Systems Division staff stationed at Fermilab for producing such splendid magnets. We also thank the staff of the Fermilab Magnet Test Facility for their hard work that has allowed so much lovely data to be collected in such a short time.

\section{REFERENCES}

1. R.C. Gupta, et al., SSC $50 \mathrm{~mm}$ Dipole Cross-Section, Supercollider 3, p. 587, 1991, J. Nonte, ed.

2. J. Strait, et al., Mechanical Design of the 2D Cross-Section of the SSC Collider Dipole Magnet, Proc. of the 1991 IEEE Particle Accelerator Conf., p. 2176, 1991, L. Lizama and J. Chew, eds.

3. J.S. Brandt, et al., Coil End Design for the SSC Collider Dipole Magnet, ibid., p. 2182.

4. S.W. Delchamps, et al., SSC Collider Dipole Magnet End Mechanical Design, ibid., p. 2185.

5. C.L. Goodzeit et al., Measurement of Intemal Forces in Superconducting Accelerator Magnets with Strain Gauge Transducers, IEEE Trans, Mag. Vol. 25, p. 1463, 1989.

6. P.O. Mazur and T.J. Peterson, A Cryogenic Test Stand for Full-Length SSC Magnets with Superfluid Capability, Advances in Cryogenics, Vol. 35, p.785, 1990.

7. J. Strait, et al., Fermilab R\&D Test Facility for SSC Magnets, Supercollider 1 p. 551, 1989, M. McAshan, ed.

8. M. Wake, et al., Mechanical Behavior of Fermilab/General Dynamics Built $15 \mathrm{~m}$ SSC Collider Dipoles, presented at the 4th Intemational Industrial Symposium on the Supercollider New Orleans, LA, March 4-6, 1992.

9. S. Delchamps, et al., Magnetic Field Measurements of Fermilab/General Dynamics Built Full Scale SSC Collider Dipole Magnets, presented at the 4th International Industrial Symposium on the Supercollider, New Orleans, LA, March 4-6, 1992.

10. M.A. Green, Calculating the Jc, B, T Surface for Niobium Titanium Using a Reduced State Model, IEEE Trans. Mag. Vol. 25, p 2119, 1989.

11. C. Haddock, et al., SSC Dipole Quench Protection Heater Test Results, Proc of the 1991 IEEE Particle Accelerator Conf., p. 2215, 1991, L. Lizama and J. Chew, eds.

12. G. Snitchler, private communication.

13. M.J. Lamm, et al., Bipolar and Unipolar Tests of $1.5 \mathrm{~m}$ Model SSC Collider Dipole Magnets at Fermilab, Broc of the 1991 IEEE Particle Accelerator Conf., p. 2191.

14. M.J. Lamm et al., Results from the Fermilab $1.5 \mathrm{~m}$ Model Magnet Program, presented at the 4 th International Industrial Symposium on the Supercollider, New Orleans, LA, March 4-6, 1992. 